\title{
Manufacturing of Surface Nanostructured Fibers Featuring an Antibacterial Effect by Magnetic Field Transportation of Magnetite@Silver Core-Shell Nanoparticles
}

\author{
Roy Buschbeck ${ }^{1,2}$, Franziska Lüttich ${ }^{1,2}$, Sebastian Spange1, Ronny Köcher1, Michael Röder¹, \\ Andreas Heft' ${ }^{1}$, Bernd Grünler ${ }^{1}$, Arnd Schimanski ${ }^{1}$, Heinrich Lang ${ }^{2}$ \\ ${ }^{1}$ Surface Engineering, Innovent e. V. Technology Development, Jena, Germany \\ ${ }^{2}$ Inorganic Chemistry, Institute of Chemistry, TechnischeUniversität Chemnitz, Chemnitz, Germany \\ Email: rb@innovent-jena.de
}

How to cite this paper: Buschbeck, R., Lüttich, F., Spange, S., Köcher, R., Röder, M., Heft, A., Grünler, B., Schimanski, A. and Lang, H. (2017) Manufacturing of Surface Nanostructured Fibers Featuring an Antibacterial Effect by Magnetic Field Transportation of Magnetite@Silver Core-Shell Nanoparticles. Journal of Materials Science and Chemical Engineering, 5, 1-16.

https://doi.org/10.4236/msce.2017.512001

Received: November 3, 2017

Accepted: December 4, 2017

Published: December 7, 2017

Copyright $\odot 2017$ by authors and Scientific Research Publishing Inc. This work is licensed under the Creative Commons Attribution International License (CC BY 4.0).

http://creativecommons.org/licenses/by/4.0/ (c) (i) Open Access

\begin{abstract}
Magnetic core-shell nanoparticles of type $\mathrm{Fe}_{3} \mathrm{O}_{4} @ \mathrm{Ag}$ were synthesized in gram scale following a combined co-precipitation phase-transfer method and afterwards, processed to nanoparticle polymer (polypropylene and polyamide) composites. These composites were used as sheath material for the fabrication of core-sheath fibers. During the melt spinning process, a magnetic field was applied around the roving, whereby the particles move in the still liquid sheath polymer towards the surface. The produced fiber materials were investigated by AFM showing a nanostructuring of the surface, which was indirectly confirmed by determination of a slight surface tension lowering. Nanoparticle movement was shown by cross-section SEM and EDX measurements. The antibacterial activity of the spun fibers was proven by contacting them with Escherichia coli. A long-term stability of this effect was observable by carrying out a standard washability test. In contrast to previous works this new approach uses no deposition technique to introduce surface changes. It rather applies a magnetic force to move appropriately equipped nanoparticles from the inside of the fiber to the surface. This leads in only one step to a strong superficial anchoring of the particles resulting in a unique combination of long-term stable antibacterial and improved anti-soiling effects.
\end{abstract}

\section{Keywords}

Nanocomposites, Polymer Fibers, Core-Shell Nanoparticles, Magnetic Field Treatment, Nanostructured Surface 


\section{Introduction}

In recent decades, the fast-paced development of various kinds of nanoparticles (NP) enormously influenced the research on textile fibers featuring new unique properties [1]. Meanwhile, various types of nanofunctionalized fibers and textiles were developed and partly produced in an industrial scale. In this respect, a special meaning is entitled to silver nanoparticle functionalized fibers having an antimicrobial effect [2].

Silver possesses an antibacterial and fungicidal effect [3]. This is based on the release of $\mathrm{Ag}^{+}$ions which inhibit the metabolism of bacteria and fungi. That's why silver is already in use for drinking water treatment and disinfection of wounds for a very long time. In recent decades, the development of other active, mostly organic substances replaced silver in many cases. The rediscovery of silver as antibacterial agent in the last years is reasoned by the fast-paced development of nanotechnology [4]. Nanoparticles possess an enormous surface compared to bulk material and are therefore extremely reactive, which may also cause problems because the effects of NPs to the human body are not completely understood until now. Nevertheless, nowadays silver NPs are extensively used in the medical sector for bandaging materials, medical devices or in nanogels and nanolotions [4].

Currently, silver coated fibers/textiles are generated either by deposition of silver from the gas phase by sputtering [5] [6] [7] or from solution by immerse plating [8] [9] [10] [11] [12] and sol gel processing [13]. Therefore, nanoparticles [8] [10] as well as thin layers [5] [6] are used. The benefits of using NPs as compared to coatings are given either in processing and material saving as well as in a much higher antibacterial activity. The high reactivity of nanostructures predestines them for the production of fibers possessing antibacterial properties. The problem which still needs to be solved is the bonding of the particles to the substrates [8] [9] [14]. A promising approach to inhibit leaching, describes A. Gedanken who deposited silver NPs onto different polymer fibers in aquatic solution using ultrasonication for partially melting the fiber polymer [10]. Silver leaching from nanofunctionalized devices and textiles [15] [16] and its distribution in the environment is because of the antibacterial effect intensively discussed [16] [17] [18] [19]. According to studies at ETH Zurich in 2010, 15\% of released silver in the EU are sourced from biocidal plastics and textiles [20]. This study also verifies that these amounts are not harmful for microorganisms in sewage treatment plants or in aquatic ecosystems. The same result expresses an actual study about the detection of silver NPs in surface waters [21]. Nevertheless, it should be pursued to minimize the release of silver in the environment not only from an economical point of view.

In this study we present a new approach to functionalize polymer (PP and PA) fiber surfaces with silver coated nanoparticles. By using polymer composites containing superparamagnetic $\mathrm{Fe}_{3} \mathrm{O}_{4} @ \mathrm{Ag}$ core-shell NPs for fiber spinning in a strong magnetic field it is possible to concentrate nano-silver at the fiber surface. 
The produced synthetic fibers possess a long-term antibacterial behavior and a partly nanostructured surface.

\section{Experimental}

Scheme 1 provides an overview of the entire process starting with nanoparticle syntheses, followed by producing the particle-polymer compound and applying it in a magnetic field supported fiber spinning process.

The magnetite@silver core-shell nanoparticles were synthesized by co-precipitation from a $\mathrm{Fe}(\mathrm{II})$ - and a $\mathrm{Fe}(\mathrm{III})$-salt solution followed by addition and reduction of $\left[\mathrm{Ag}\left(\mathrm{NH}_{3}\right)_{2}\right]^{+}$according to modified procedures following publications from Sun [22] and Peuker [23] [24]. The received bifunctional (magnetic core, antibacterial sheath) nanoparticles were processed to a nanoparticle-polymer composite which were used as sheath material in a melt spinning process. Around the hot fiber, directly after the spinning nozzle, a strong magnetic quadrupole was arranged to pull the particles to the surface while the fiber passes through. The synthesized NPs were characterized by transmission electron microscopy (TEM), atomic absorption spectroscopy (AAS) and magnetic measurements. The properties of the nanofunctionalized fibers were tested by atomic force microscopy (AFM), high resolution scanning electron microscopy (HR-SEM) and energy dispersive X-ray spectroscopy (EDX). The nanostructured fiber surface was furthermore investigated by contact angle measurements. The antibacterial activity of the nanoparticles and the modified fibers was tested against $E$. coli bacteria. Finally, the long-term stability of the antibacterial activity was identified using a standard washability test.

\subsection{Materials}

Chemicals for nanoparticle synthesis were purchased from commercial sources

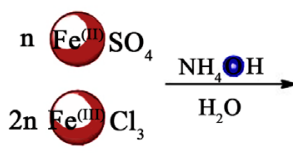

Precursor

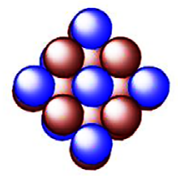

$\mathrm{Fe}_{3} \mathrm{O}_{4}$-Nanoparticle

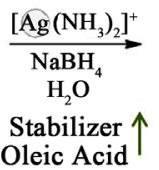

Oleic Acid

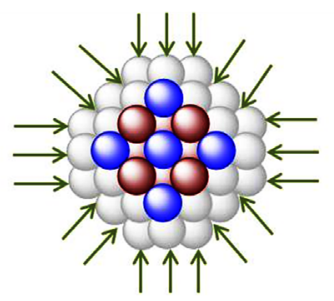

Stabilized Core-Shell-NP $\left(\mathrm{Fe}_{3} \mathrm{O}_{4} @ \mathrm{Ag}\right)$

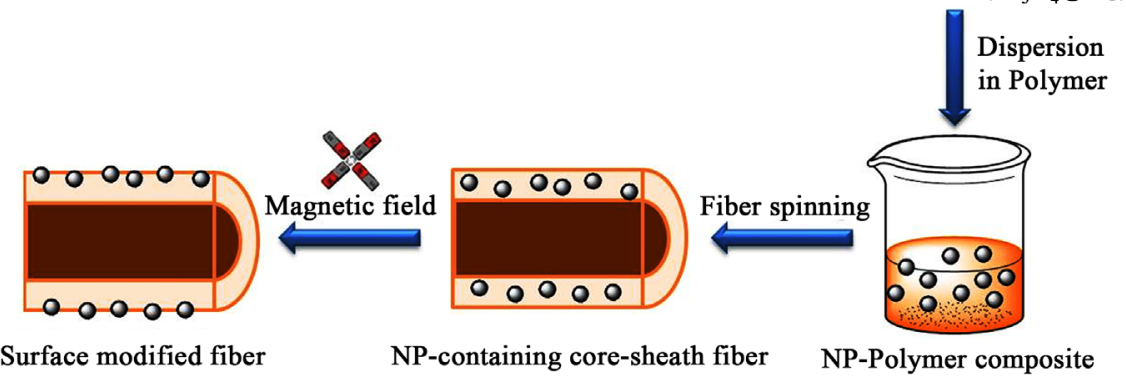

Scheme 1. Overview of the process steps: core-shell nanoparticle synthesis, dispersion, magnetic field-supported fiber spinning. 
and used without further purification. Commercial available low-melting polypropylene (PP, Braskem H214), high-melting polypropylene (PP, Moplen $\mathrm{HP} 456 \mathrm{H}$ ) and polyamide 6 (PA 6, Ultramid ${ }^{\circledR}$ B27) were used as materials for compounding and fiber production.

\subsection{Nanoparticle Synthesis}

$\mathrm{Fe}_{3} \mathrm{O}_{4} @ \mathrm{Ag}$ nanoparticles were synthesized by a modified method published by Sun and coworkers [22]. A phase transfer method for pure magnetite nanoparticles described by Peuker was used as a basis for the work-up procedure of the core-shell particles [23] [24].

Amounts of $4.85 \mathrm{~g}(17.4 \mathrm{mmol})$ of $\mathrm{FeCl}_{3} \cdot 6 \mathrm{H}_{2} \mathrm{O}$ and $2.5 \mathrm{~g}(9.25 \mathrm{mmol})$ of $\mathrm{Fe}-$ $\mathrm{SO}_{4} \cdot 7 \mathrm{H}_{2} \mathrm{O}$ were diluted in $500 \mathrm{ml}$ water in a $2 \mathrm{~L}$ round bottomed flask. The clear solution was heated up to $70^{\circ} \mathrm{C}$ using an oil bath. A volume of $6.5 \mathrm{~mL}$ of ammonia (25 wt\% in water) were added in a single portion under vigorous stirring (homogenizer VDI 25, 13,500 $\mathrm{min}^{-1}$ ) whereby the solution turns to black. After 20 min of stirring $150 \mathrm{~mL}$ of an aquatic $\left[\mathrm{Ag}\left(\mathrm{NH}_{3}\right)_{2}\right]^{+}$solution $(1 \mathrm{~g} / \mathrm{L})$ were added followed by $200 \mathrm{~mL}$ of a $\mathrm{NaBH}_{4}$ solution $(0.83 \mathrm{mM})$ in water. Thereby, the color turns from black to dark brown. While the reaction mixture cooled down to room temperature, stirring was continued for another $30 \mathrm{~min}$. The mixture was poured into a solution of $4 \mathrm{~mL}$ ( $3.56 \mathrm{~g}, 12.6 \mathrm{mmol}$ ) oleic acid in $400 \mathrm{~mL}$ of dichloromethane. After $8 \mathrm{~h}$, the NPs were completely transmigrated into the organic phase. The aquatic phase was removed and the organic phase washed twice with $50 \mathrm{~mL}$ of deionized water. After removing the volatile matter, $2.70 \mathrm{~g}$ of a 1:1 mixture of $\mathrm{Fe}_{3} \mathrm{O}_{4} @ \mathrm{Ag}$ nanoparticles and oleic acid were received.

\subsection{Compounding}

To produce nanoparticle polymer composites a double screw extruder of type Haake Rheomax PTW 16/25 was used. The $\mathrm{Fe}_{3} \mathrm{O}_{4} @ \mathrm{Ag}$ NPs were compounded in low-melting polypropylene (Braskem $\mathrm{H} 214$ ) at $260^{\circ} \mathrm{C}$ and polyamide 6 (Ultra$\left.\mathrm{mid}^{\oplus} \mathrm{B} 27\right)$ at $240^{\circ} \mathrm{C}$ to give the master-batches containing $4.0 \%$ of particles.

\subsection{Fiber Spinning Process}

For the generation of fibers possessing core-sheath geometry a bi-component fiber spinning machine (FET Bi-Component Extrusion Module produced by Fibre Extrusion Technologies) was applied. The core material, a high-melting PP (Moplen HP456H), was combined with a mixture of a low-melting PP (Braskem $\mathrm{H} 214$ ) and different amounts of the master-batch giving varying nanoparticle concentrations in the sheath $(0,0.5,1,2 \mathrm{wt} \%)$. The molten polymers/polymer compounds were combined through a mono-hole nozzle having a diameter of 1 $\mathrm{mm}$. The adjusted core to sheath value was 80:20. The spinning temperature and the take-up speed were varied in the regions of $230^{\circ} \mathrm{C}$ to $260^{\circ} \mathrm{C}$ and 10 to 20 $\mathrm{m} / \mathrm{min}$ to optimize the effect of the magnetic field. Afterwards selected fibers were stretched using a ratio of 1:4 and 1:8. Produced filaments possess in de- 
pendence of the stretching ratio diameters of $470 \mu \mathrm{m}$ (1:1), $240 \mu \mathrm{m}$ (1:4) and 170 $\mu \mathrm{m}(1: 8)$.

\subsection{Application of the Magnetic Field}

The two self-built radial-symmetric arrays of four permanent magnets (quadrupole arrangement) were applied in series directly after the nozzle in a distance of $5 \mathrm{~cm}$ (Figure 1). The four magnets of each array consist of six cylindrical permanent magnets (NE155 produced by IBS) each, feature coned pole shoes and their distance is adjustable for concentrating the magnetic field as close as possible to the fiber. The mounting of the magnets is made from brass, is hinged for the possibility to insert the fiber and possesses a water-cooling to save the magnets from the high temperatures close to the nozzle. To enhance the magnetic field strength in the center and to weaken the stray field around the construction two magnets each were coupled by an iron bracket.

The magnetic field in the center of the device was measured at two different tip distances ( 3 and $8 \mathrm{~mm}$ ) using a magnetic field scanner (Senis MMS-1-RS) to estimate the field strength at the surface of the fiber. At a fiber diameter of $1 \mathrm{~mm}$ $220 \mathrm{mT}$ ( $3 \mathrm{~mm}$ distance) or $22 \mathrm{mT}$ ( $8 \mathrm{~mm}$ distance) effect the NPs close to the surface of the fiber (Figure 2). To maximize the force, pulling the particles to the surface, the tip distance should be minimized. The lowest in practice realizable distance between the fiber surface and the pole shoe tips is due to the slight fiber fluctuation $1 \mathrm{~mm}$. Lower values lead to fiber-pole shoe contacts, resulting in a spinning process stop, due to a severed fiber.

\subsection{Analytical Equipment and Methods}

Magnetic field strength was measured using the Senis magnetic field scanner MMS-1-RS. TEM imaging of nanoparticles was performed with a PHILIPS CM $20 \mathrm{FEG}$ instrument operated at $200 \mathrm{kV}$. SEM imaging and EDX analyses were carried out with a SEM Supra 55 VP from Carl Zeiss AG equipped with the EDX System Quantax from Bruker. For recording of AFM images an MFP 3D from Asylum Research was applied. Thermo Scientific iCE 3000 System was used for atomic absorption spectroscopy. Magnetic Measurements were performed with a Vibrating Sample Magnetometer (VSM) EZ09 from MicroSense.
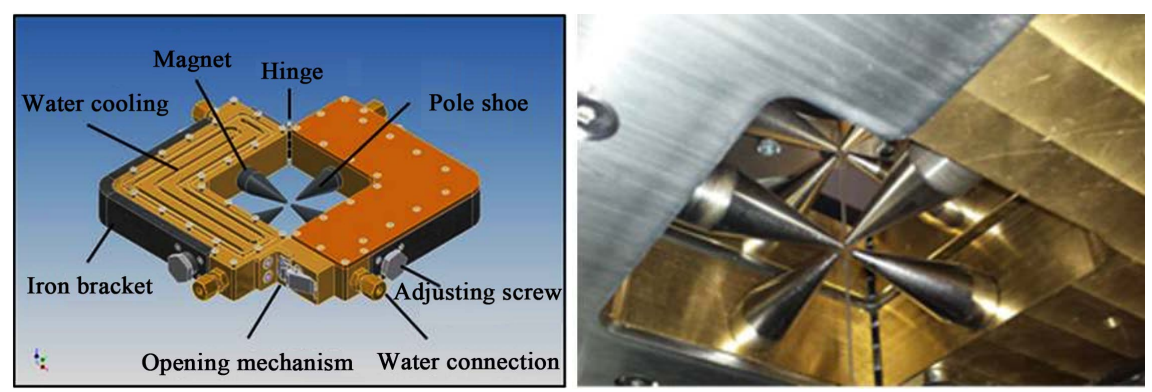

Figure 1. Construction drawing of the magnet mounting including the four quadrupole arranged magnets with pole shoes (left) and the assembled double-stacked mounting with a centered laid-in fiber (right). 


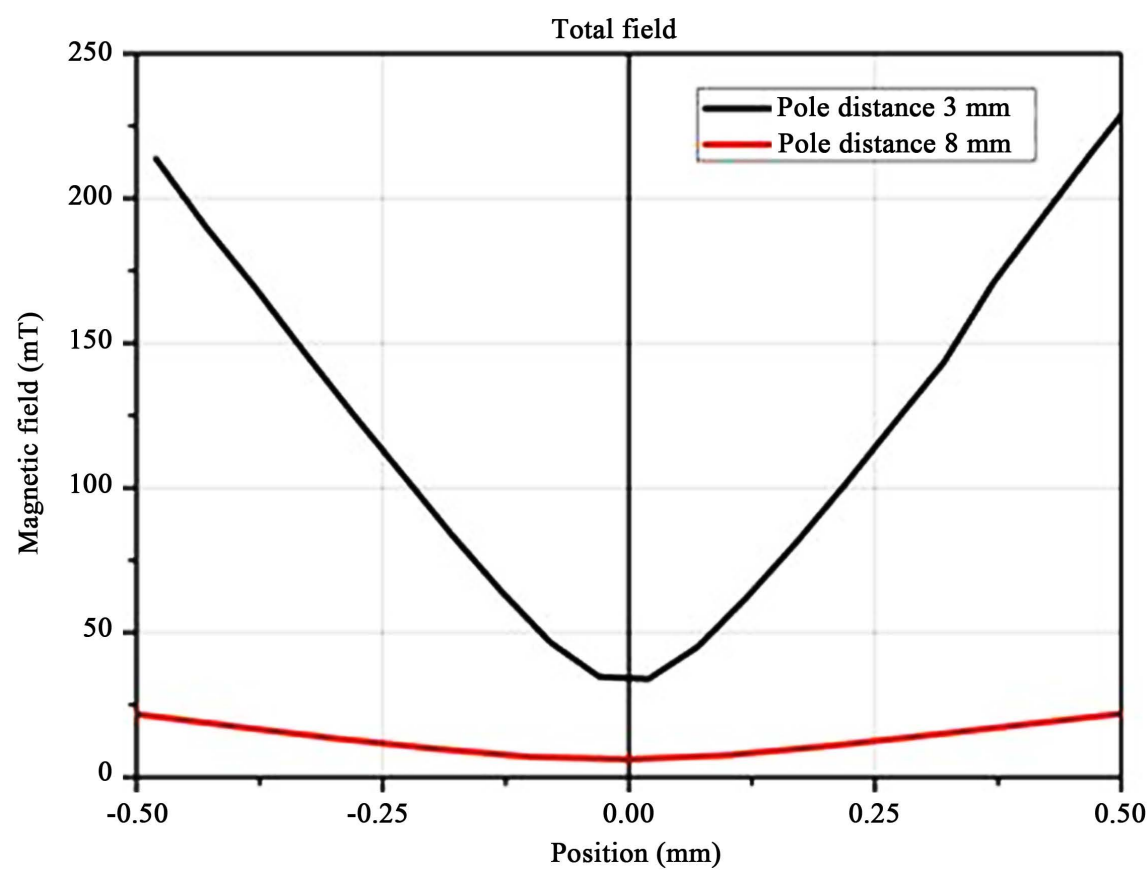

Figure 2. Effective magnetic field in the center of the quadrupole arrangement against the distance between the pole tips ( 3 and $8 \mathrm{~mm}$ ).

\subsubsection{Antibacterial Evaluation}

The tests to evaluate the antibacterial effect of the produced materials were performed using an Escherichia coli HB101 strain. The BTG microbial cell viability assay (Promega, Madison, Wi, USA) was used to spot bacterial injury on the basis of the intracellular ATP content of the cells. The nanoparticles were tested as compressed pellets. The antibacterial activity of fiber materials was evaluated using rolled up fiber pieces of $18 \mathrm{~cm}$ length. For this the samples were immersed in $0.5 \mathrm{~mL}$ of an $E$. coli suspension (about $1 \times 10^{6}$ cells per $\mathrm{mL}$ ) in physiological saline for $3 \mathrm{~h}$. After this incubation step a volume of $50 \mu \mathrm{L}$ were transferred into 96 well plates (three replicates) and $50 \mu \mathrm{L}$ of BTG reagent was added to each sample. In the end, the analysis of the antibacterial activity of the exposed samples was done by measuring the intensity of the luminescence signal, which is proportional to the ATP concentration of the bacteria cells. A decrease of the ATP content in comparison to the unaffected E. coli suspension indicated an inhibition of the energy metabolism within the cells and with it cellular damage, which is shown as a decreasing luminescence signal indicating an antibacterial effect.

\subsubsection{Contact Angle Analysis}

For contact angle measurements the fibers were rinsed with ethanol and dried at $50^{\circ} \mathrm{C}$ using an air blower. Contact angles were measured for three different liquids (water, methylene iodide and ethylene glycol) possessing different surface tensions comprised of varying dispersive and polar grades (Table 1 ). Therefore five droplets $(0.3 \mu \mathrm{L})$ of each solvent were applied to a single fiber and measured using the drop shape analyzer DSA 100 from Krüss $\mathrm{GmbH}$. The average values 
Table 1. Surface tension data for the used solvents.

\begin{tabular}{cccc}
\hline Liquids & $\begin{array}{c}\text { Surface tension } \\
\gamma[\mathrm{mN} / \mathrm{m}]\end{array}$ & $\begin{array}{c}\text { Dispersive grade } \\
\gamma_{\mathrm{D}}[\mathrm{mN} / \mathrm{m}]\end{array}$ & $\begin{array}{c}\text { Polar grade } \\
\gamma_{\mathrm{P}}[\mathrm{mN} / \mathrm{m}]\end{array}$ \\
\hline Water & 72.8 & 21.8 & 51.0 \\
Methylene iodide & 50.8 & 50.8 & 0.0 \\
Ethylene glycol & 47.7 & 30.9 & 16.8 \\
\hline
\end{tabular}

obtained for the different solvents were used to calculate the surface energies and the polar and dispersive grades occurred using the method of Owens and Wendt [25].

\subsubsection{Washability Test}

Long-term stability of the produced fibers was analyzed using a standard washability test under withering conditions. Therefore the samples were washed ten times at $60^{\circ} \mathrm{C}$ for $105 \mathrm{~min}$ with an additional loading of $2 \mathrm{~kg}$. After each cycle the fibers were whizzed at $1200 \mathrm{~min}^{-1}$.

\section{Results and Discussion}

\subsection{Nanoparticle Synthesis and Characterization}

Nanocrystalline magnetite was synthesized in gram-scale via co-precipitation of $\mathrm{Fe}(\mathrm{II})$ and $\mathrm{Fe}$ (III) salts in an aqueous solution using ammonia as precipitation reagent. The silver coating was introduced by adding a solution of diamminesilver (I) nitrate to the magnetite dispersion followed by the $\mathrm{NaBH}_{4}$-solution for reduction. During the reaction, as no stabilizing agent was present, the mixture was vigorously stirred to avoid strong agglomeration. Once the reaction has finished (after $45 \mathrm{~min}$ ) the small particle agglomerates were deagglomerized by a phase transfer procedure according to literature [23]. The NP dispersion was added to a solution of oleic acid in dichloromethane. The particle agglomerates sink to the interface where oleic acid molecules are concentrated. These long-chain molecules bind chemically to the particle surfaces and dissolve out single NPs into the organic phase. After phase separation and removal of the solvent the particles are obtained as a powder, paste or oil, depending on the amount of oleic acid, which was used for the phase transfer procedure (Figure 3).

The resulting $\mathrm{Fe}_{3} \mathrm{O}_{4} @ \mathrm{Ag}$ NPs are mainly spherical in shape and possess a mean diameter of $13.3 \mathrm{~nm}$ with a standard deviation of $2.9 \mathrm{~nm}$ (Figure 4) which could be verified by TEM imaging. Temperature dependent magnetic measurements show a nearly superparamagnetic behavior of the magnetite cores at a temperature of $250^{\circ} \mathrm{C}$ (Table 2) which vaguely correlates to the fiber spinning process temperature (see below). A superparamagnetic behavior maximizes the force, which is exerted to the magnetic nanoparticles during the process. This is important to extend the distance which every single particle can cover from inside the fiber to the surface, while passing the magnetic field. In Table 2 the results of the magnetic measurements of the magnetite core particles are summarized. 


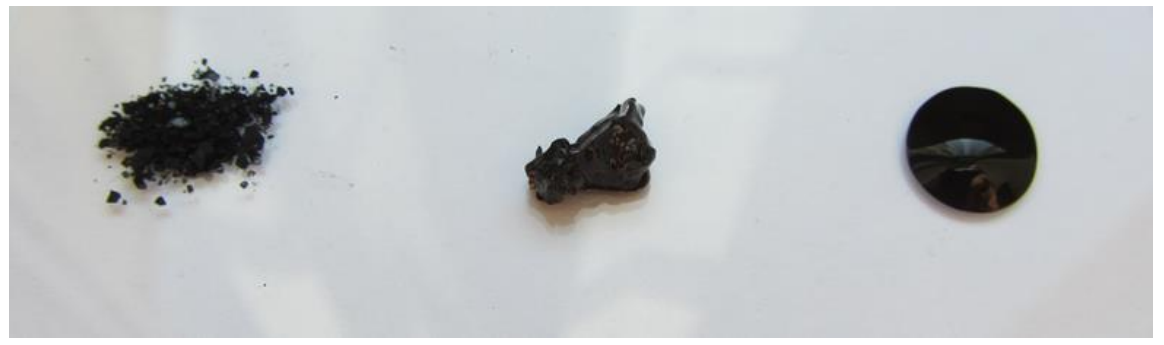

Figure 3. Different consistence of nanoparticle oleic acid dispersions depending on the particle content (left: powder containing $90 \mathrm{wt} \%$ NPs, middle: paste containing $50 \mathrm{wt} \%$ NPs and right: oil containing $25 \mathrm{wt} \%$ NPs.
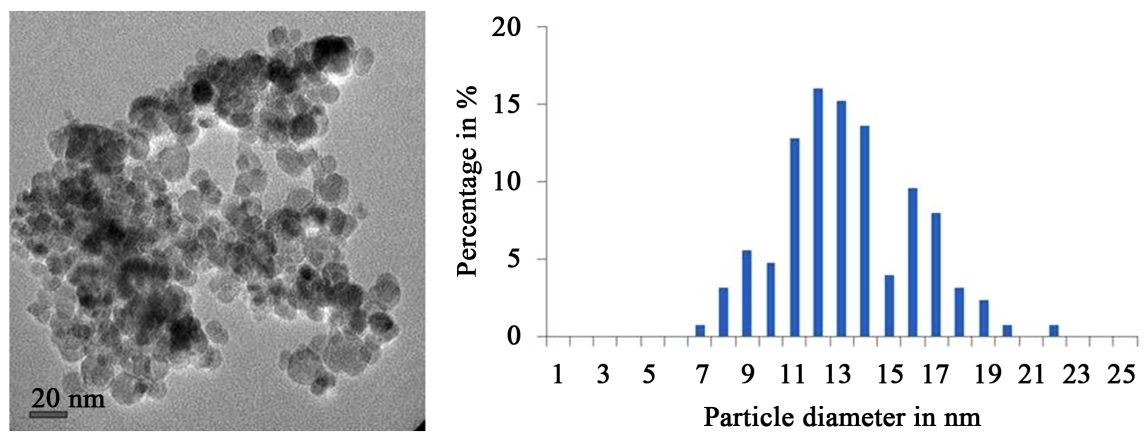

Figure 4. TEM image of synthesized magnetite@silver nanoparticles (left) and corresponding size distribution (right).

Table 2. Temperature dependent magnetic data for the synthesized magnetite nanoparticle cores.

\begin{tabular}{cccc}
\hline $\begin{array}{c}\text { Temperature } \\
\mathrm{T}\left[{ }^{\circ} \mathrm{C}\right]\end{array}$ & $\begin{array}{c}\text { Coercivity } \\
\mathrm{H}_{\mathrm{c}}[\mathrm{A} / \mathrm{m}]\end{array}$ & $\begin{array}{c}\text { Specific remanence } \\
\sigma_{\mathrm{R}}\left[\mathrm{Am}^{2} / \mathrm{kg}\right]\end{array}$ & $\begin{array}{c}\text { Specific saturation } \\
\text { magnetization } \\
\sigma_{\text {Sat }}\left[\mathrm{Am}{ }^{2} / \mathrm{kg}\right]\end{array}$ \\
\hline-170 & 3500 & 4.4 & 57.6 \\
25 & 186 & 0.38 & 57.2 \\
100 & 33 & 0.06 & 51.0 \\
250 & 10 & 0.013 & 54.5 \\
\hline
\end{tabular}

While the specific saturation magnetization remains nearly constant at around $55 \mathrm{Am}^{2} / \mathrm{kg}$ during heating, the coercivity and the specific remanence are decreasing from $3500 \mathrm{~A} / \mathrm{m}\left(\mathrm{H}_{\mathrm{C}}\right)$ and $4.4 \mathrm{Am}^{2} / \mathrm{kg}\left(\sigma_{\mathrm{R}}\right)$ at $-170^{\circ} \mathrm{C}$ to $10 \mathrm{~A} / \mathrm{m}$ and $0.013 \mathrm{Am}^{2} / \mathrm{kg}$ at $250^{\circ} \mathrm{C}$. The values of the magnetite@silver core-shell NPs measured at $25^{\circ} \mathrm{C}$, are in the same region as measured for the cores only $\left(\mathrm{H}_{\mathrm{C}}=\right.$ $72 \mathrm{~A} / \mathrm{m}, \sigma_{\mathrm{R}}=0.13 \mathrm{Am}^{2} / \mathrm{kg}, \sigma_{\mathrm{Sat}}=50.9 \mathrm{Am}^{2} / \mathrm{kg}$ ). The magnetic inactive silver coating implicates the slight lowering of the values.

\subsection{Compounding}

The produced nano-paste possessing a particle content of $50 \mathrm{wt} \%$ was used for the preparation of the master-batches by compounding it with two different po- 
lymers (PP and PA 6) using a conventional twin-screw extruder to give the respective compound materials containing $4 \mathrm{wt} \%$ of the NPs each. The particles are well dispersed in both polymers-no agglomerates are visible in the microscopic view-resulting in uniformly light (PP) or dark (PA 6) brown colors of the material (Figure 5).

\subsection{Fiber Production}

For fiber production a bi-component fiber spinning machine was used. This facility makes it possible to generate filaments possessing core-sheath geometry. Such a fiber structure has some important benefits for the process management: 1) the amount of nanoparticle material needed can be minimized by using it only for the sheath composite, 2) the way of the particles to the surface is much shorter, 3) most of the magnetic material is concentrated in regions with a high magnetic field and not in the center of the fiber, where the field is zero (Figure 6) and 4) the possibility to use two different polymers for the core and the sheath possessing different viscosities at one temperature is given. This is especially important for the particle migration to the surface. To maximize this effect low polymer viscosities are necessary. At the same time a relatively high viscosity is needed for the preparation of a homogeneous fiber, which can be provided by
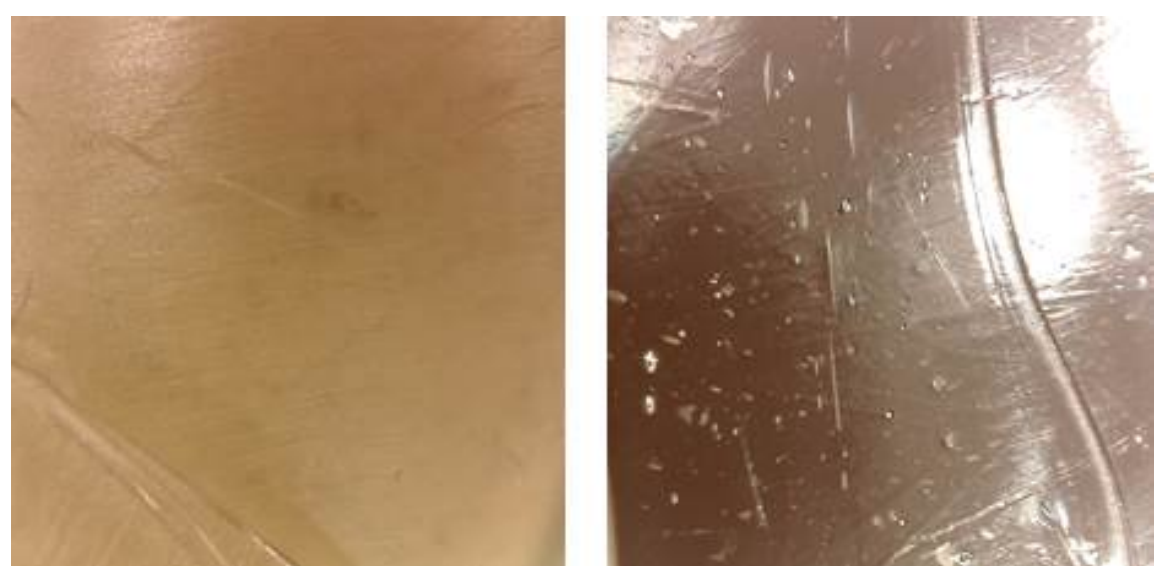

Figure 5. Microscopic view (correspond to $7 \times 7 \mathrm{~mm}^{2}$ ) of the produced composites from the synthesized magnetic core-shell nanoparticles in PP (left) and PA 6 (right).

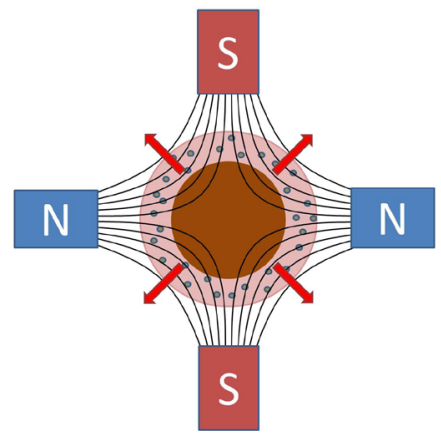

Figure 6. Schematic view of a core-sheath fiber cross-section in a quadrupole magnetic field. 
using a high-melting polymer as core material. The polypropylene we used as core material has at $230^{\circ} \mathrm{C}$ a 13 times higher viscosity than the sheath material.

For the generation of uniform core-sheath fibers some parameters of the spinning process must be adjusted to the nanofunctionalized system (Figure 7). The most important parameter is the spinning temperature which influences the viscosity of the polymer. The higher the temperature of the fiber in the magnetic field, the higher the mobility of the nanoparticles in the polymer phase will be. To maximize the number of particles reaching the fiber surface the temperature must be as high as possible. A parameter which is indirectly coupled to the temperature is the reeling speed which should be high to make the process more cost efficient. Though for the process of particle moving a longer retention time in the magnetic field is desirable. To increase the number of particles at the fiber surface after the process the particle concentration in the composite material should be maximized without influencing the spinning properties too much. The thickness of the fiber sheath containing the nanomaterial should be minimized in order to economize on expensive nanomaterials because particles, which are located in the inner fiber, will never reach the surface as the magnetic field in the center of the fiber is too low and the way to the surface too long. Therefore, they would remain wasted inside and neither conduce to a nanostructured surface nor an antibacterial effect. The difficulty was to find the optimum of all these interoperable parameters. Table 3 shows the values of the adjusted parameters (realized value) in comparison to the aimed values which would be optimal for each parameter without interconnections.
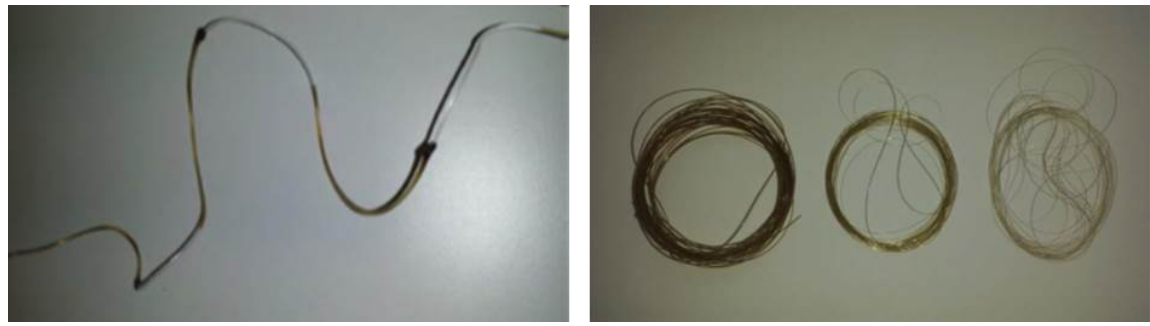

Figure 7. PP-based core-sheath fiber with partially torn sheath due to incompatible parameters (left); homogeneous PP-based core-sheath fibers possessing different draft rates, from left to right 1:1, 1:4 and 1:8 (right).

Table 3. Optimization of spinning parameters.

\begin{tabular}{ccc}
\hline Parameter & $\begin{array}{c}\text { Aimed region } \\
\text { (individual parameter) }\end{array}$ & $\begin{array}{c}\text { Optimized value } \\
\text { (interconnected parameter) }\end{array}$ \\
\hline $\begin{array}{c}\text { Particle content } \\
\text { Core-sheath rate }\end{array}$ & up to $4 \mathrm{wt} \%$ & 0.5 to $2 \mathrm{wt} \%$ \\
Spinning temperature & up to $90: 10$ & $80: 20$ \\
Reeling speed & up to $300^{\circ} \mathrm{C}$ & $230^{\circ} \mathrm{C}$ to $245^{\circ} \mathrm{C}$ \\
Draft & down to $10 \mathrm{~m} / \mathrm{min}$ & $20 \mathrm{~m} / \mathrm{min}$ \\
& up to $1: 10$ & $1: 8$
\end{tabular}




\subsection{Fiber Characterization}

The produced fibers were investigated on a submicroscopic level to characterize their surfaces in comparison to the unmodified ones. To prove the migration of the NPs in the magnetic field during fiber spinning the NP distribution in the sheath of a PP-fiber without field influence was compared to a filament which passed through the quadrupole magnetic field. Therefore, the cross-sections of the fibers were investigated using EDX spectroscopy. Figure 8 shows beside the SEM image of the cross-section (left) two EDX spectra illustrating the iron elemental contribution in the sheath. In both of these pictures a nearly homogenous pattern of red dots is identifiable, but in the image showing the magnetic field exposed filament (right) an accumulation of particles at the fiber surface is apparent.

AFM studies of the fiber surfaces partly confirm this result showing a conspicuous nanostructuring of the magnetic field exposed fiber (Figure 9, right) which overlays the typical microstructure of the untreated polymer fiber (Figure 9, left). However, it must be mentioned that this effect is not constantly visible on the whole fiber surface. Some regions remain nearly unchanged by passing through the magnetic assembly. This fact is beside the usual variations of polymer fiber surfaces probably attributable to the slight oscillation of the fiber during fabrication which minimally changes the distance of their surface to the pole shoe cones. That means also a fluctuation of the effective magnetic field for the nanoparticles and at high distances a tractive force which is too low for a
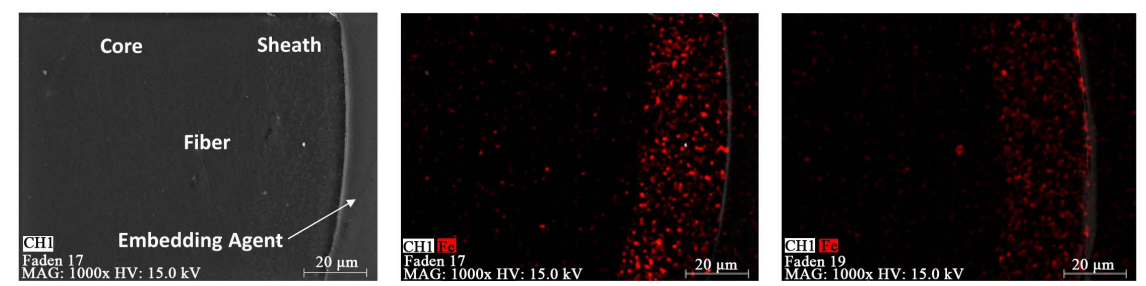

Figure 8. Cross-section images of modified PP core-sheath fibers: SEM image (left), EDX images showing Fe contribution of a fiber spun without (center) and with (right) a magnetic field. The other conditions remain constant ( $1 \mathrm{wt} \% \mathrm{NP}$-content in the sheath material, $230^{\circ} \mathrm{C}$ spinning temperature, $20 \mathrm{~m} / \mathrm{min}$ reeling speed, no draft).
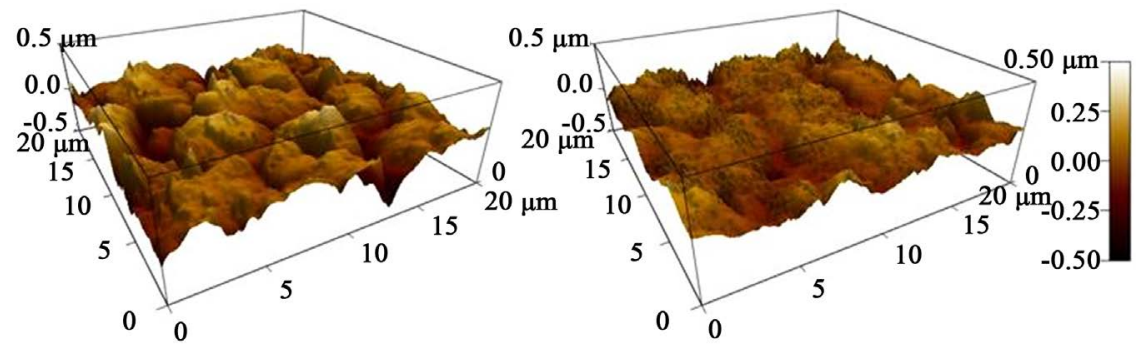

Figure 9. Three-dimensional AFM images of modified PA fiber surfaces spun without (left) and with (right) a magnetic field. The other conditions remain constant ( $1 \mathrm{wt} \%$ $\mathrm{NP}$-content in the sheath material, $245^{\circ} \mathrm{C}$ spinning temperature, $20 \mathrm{~m} / \mathrm{min}$ reeling speed, no draft). 
distinct particle movement to the surface. The nanostructuring effect is also more present for the PA than for PP fibers. In this context not only the type of polymer but also the higher possible spinning temperature for PA (PP: $230^{\circ} \mathrm{C}$, PA: $245^{\circ} \mathrm{C}$ ) is a reason for this behavior.

To show if the partly nanostructured surfaces are able to lower the surface energy and improve the dirt-repelling properties of the fibers contact angle measurements at single filaments were applied. As anticipated from microscopic results the detectable effect on the surface energy is low. Nevertheless, an influence of the magnetic field as well as of the NP concentration is visible (Figure 10). Excluding the sample without any particles a growing NP concentration in the sheath composite lowers the surface energy even without exposure to magnetic field. Applying the magnetic field leads to a further slight lowering. Even if this effect is very low, it shows a nanofunctionalization of the fiber surface, caused by the incorporated core-shell NPs. A clear influence of other spinning parameters like temperature and reeling speed was not obvious. This can be explained by the low possible variation of these parameters (spinning temperature: $220^{\circ} \mathrm{C}-245^{\circ} \mathrm{C}$, reeling speed: $10-20 \mathrm{~m} / \mathrm{min}$ ), which was attributed to a homogeneous fiber and a stable fiber running.

Beside the reduction of the surface energy by nanostructuring of the fibers caused by the magnetic core of the used core-shell NPs an antibacterial effect should be introduced by the silver shells of the particles. To quantify this behavior, antibacterial tests using E. coli bacteria were performed with the synthesized nanoparticles themselves as well as with the functionalized fibers.

Therefore, the magnetite and the $\mathrm{Fe}_{3} \mathrm{O}_{4} @ \mathrm{Ag}$ NPs were first investigated by compressing them to pellets and expose them to the pre-cultivated $E$. coli bacteria suspension. The results verify that already the uncoated $\mathrm{Fe}_{3} \mathrm{O}_{4}$-NPs show a

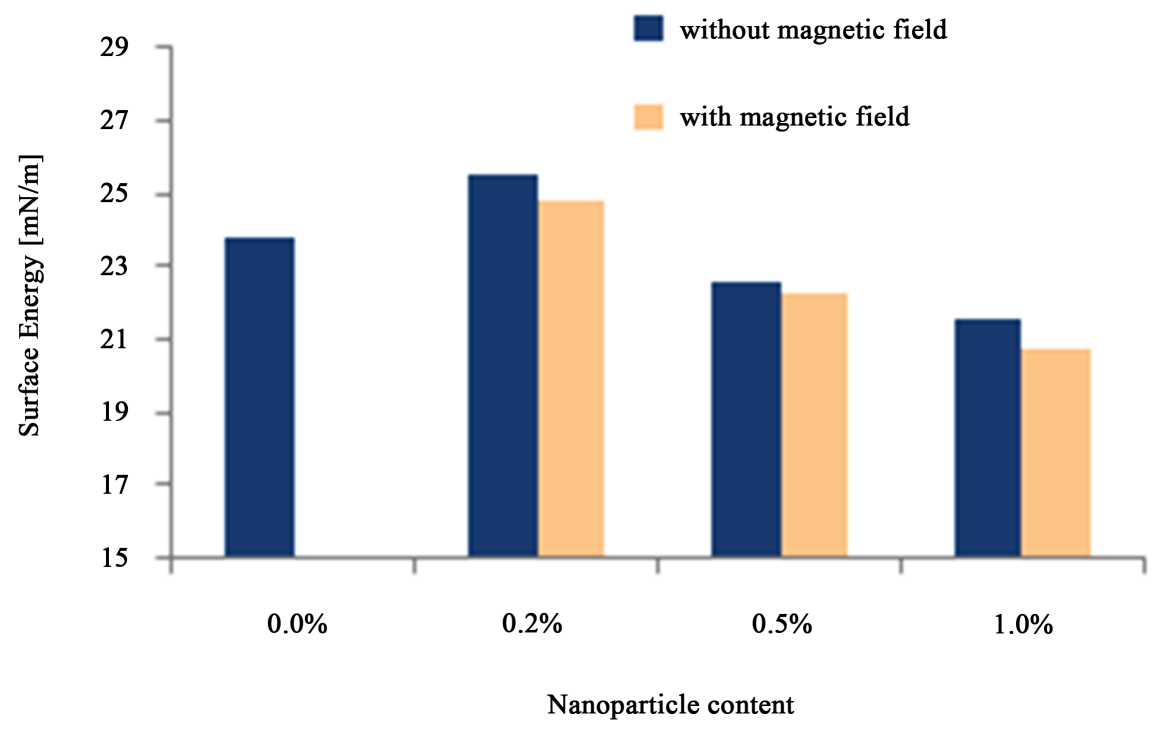

Figure 10. Bar diagram illustrating the influence of the nanoparticle content and the magnetic field to the surface energy of PP core-sheath fibers $\left(230^{\circ} \mathrm{C}\right.$ spinning temperature, 20 $\mathrm{m} / \mathrm{min}$ reeling speed, no draft). 
good antibacterial effect by lowering the bacteria growth by the power of ten compared with the reference (Figure 11, left diagram). The respective core-shell particles achieve naturally a much better performance. The bacterial multiplication drops down to $0.2 \%$ of the normal rate, which indicates the very strong antibacterial effect of the nano-silver coated particles.

The same investigations were performed for the nanofunctionalized fibers (Figure 11, right diagram). The sheaths of the fibers tested contain a nanoparticle concentration of $1 \mathrm{wt} \%$. The polypropylene fibers (PP) containing nano-magnetite show a reduced bacteria growth ( $70 \%$ of reference value), while the core-shell functionalized filaments reach $40 \%$. The best antibacterial effect indicates the polyamide fiber with the $\mathrm{Fe}_{3} \mathrm{O}_{4} @ \mathrm{Ag}$ NPs reaching $25 \%$ of the reference sample. This can be explained by the higher polarity of PA compared with $P P$ bringing a better interaction of the bacteria suspension to the fiber surface and hence the silver particles. A significant influence of the magnetic field treatment is not observable. Astonishingly, the bacterial growth values seem to be slightly higher using fibers produced with a magnetic field (samples indicated by (2)) than without it (1), but the differences are within the error margins and hence not significant.

For proving the long-term stability of the antibacterial effect and hence the minimized leeching of the silver three selected filaments were tested using a standard washability test under withering conditions. From these three samples only one shows a long-term stability of the antibacterial effect while the other two loose more than $60 \%$ of that power (Figure 12). The significant difference
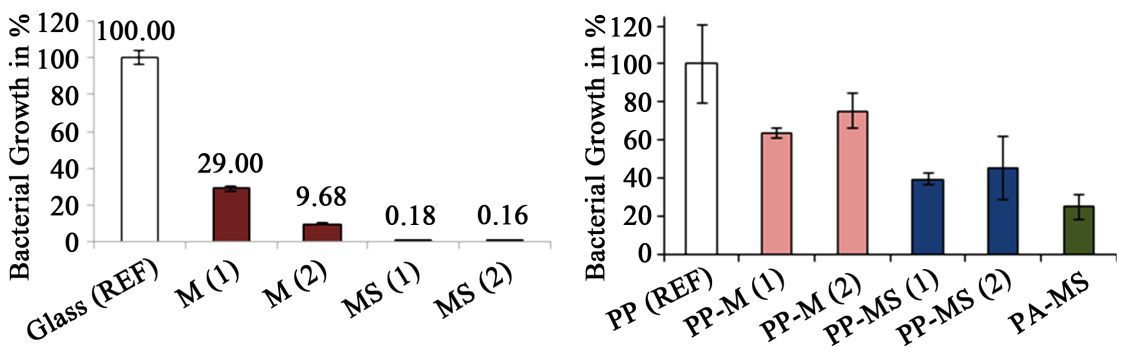

Figure 11. Bar diagrams showing nanoparticle caused reduced growth rates of $E$. coli bacteria when exposed to the pure nanoparticles (left) and the nanoparticle containing fibers (right); M-Magnetite nanoparticles, MS-Magnetite@silver core-shell nanoparticles.

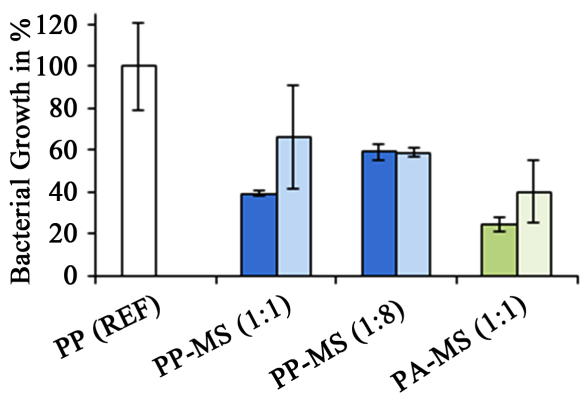

Figure 12. Bar diagram showing the results of antibacterial tests before (dark color) and after (light color) the washability test. 
between the fiber held steady and the others is the draft rate. While the undrafted filaments seem to lose silver and hence partly their antibacterial effects, the 1:8 drafted one remains unchanged. A possible explanation of this behavior may be the changes in the polymer structure which are caused by the tractive forces arising during the drafting process. The molecular chains get stretched and enclose the nanoparticles stronger than before. This probably leads to the unchanged value of the bacterial growth before and after washing.

\section{Conclusion}

The paper reports an interesting new approach to long-term stable nanostructured and antibacterial fibers. The innovative method uses bifunctional core-shell (magnetite@silver) nanoparticles which were concentrated at the core-sheath polymer fiber surface by applying a strong magnetic field during the fiber spinning process. The nanoparticle migration was proven by cross-section EDX spectroscopy showing a particle accumulation at the fiber surface and AFM microscopy indicating a nanostructuring after magnetic field treatment. The core-shell nanoparticle containing fibers possess an antibacterial effect which seems to be independent from passing the magnetic field or not. The long-term stability of this effect was reached by a 1:8 drafting of the fibers after the spinning process. The introduced surface effects are still not very strong and because of slight fiber fluctuations not strictly homogenous dispersed over the whole filaments. To increase the particle concentration could help to maximize the effects but has the disadvantage to raise also the magnetic attraction force of the whole fiber to the magnets which will lead to fiber-magnet contacts causing a complete process stop. The most promising approach to improve and unify the surface properties is to systematically elevate the fiber temperature while passing the magnetic field and to extend this field into reeling direction. Therefore further investigations must be carried out to get the process ready for industrial application.

\section{Acknowledgements}

We acknowledge the Bundesministerium für Wirtschaft und Technologie (BMWi) for the financial support of this research (grant no. MF 130037). We furthermore thank the Thuringian Institute of Textile and Plastics Research (TITK) for a fruitful collaboration.

\section{References}

[1] Gowri, S., Almeida, L., Amorim, T., Carneiro, N., Souto, A.P. and Esteves, M.F. (2010) Polymer Nanocomposites for Multifunctional Finishing of Textiles-A Review. Textile Research Journal, 80, 1290-306. http://doi.org/10.1177/0040517509357652

[2] Dastjerdi, R., Montazer, M. and Shahsavan, S. (2010) A Novel Technique for Producing Durable Multifunctional Textiles Using Nanocomposite Coating. Colloids and Surfaces B: Biointerfaces, 81, 32-41. 
http://doi.org/10.1016/j.colsurfb.2010.06.023

[3] Cliver, D.O., Sarles, W.B., Foell, W.K. and Goepfert, J.M. (1971) Biocidical Effects of Silver. Contract NAS 9-9300 Final Technical Report. University of Wisconsin, 5.

[4] Rai, M., Yadav, A. and Gade, A. (2009) Silver Nanoparticles as a New Generation of Antimicrobials. Biotechnology Advances, 27, 76-83. http://doi.org/10.1016/j.biotechadv.2008.09.002

[5] Scholz, J., Nocke, G., Hollstein, F. and Weissbach, A. (2005) Investigations on Fabrics Coated with Precious Metals Using the Magnetron Sputter Technique With Regard to Their Anti-Microbial Properties. Surface and Coatings Technology, 192, 252-6. http://doi.org/10.1016/j.surfcoat.2004.05.036

[6] Baghriche, O., Ruales, C., Sanjines, R., Pulgarin, C., Zertal, A., Stolitchnov, I., et al. (2012) Ag-Surfaces Sputtered by DC and Pulsed DC-Magnetron Sputtering Effective in Bacterial Inactivation: Testing and Characterization. Surface and Coatings Technology, 206, 2410-2416. http://doi.org/10.1016/j.surfcoat.2011.10.041

[7] Hegemann, D., Hossain, M.M. and Balazs, D.J. (2007) Nanostructured Plasma Coatings to Obtain Multifunctional Textile Surfaces. Progress in Organic Coatings, 58, 237-240. http://doi.org/10.1016/j.porgcoat.2006.08.027

[8] Lee, H.J., Yeo, S.Y. and Jeong, S.H. (2003) Antibacterial Effect of Nanosized Silver Colloidal Solution on Textile Fabrics. Journal of Material Science, 38, 2199-204. http://doi.org/10.1023/A:1023736416361

[9] Dubas, S.T., Kumlangdudsana, P. and Potiyaraj, P. (2006) Layer-by-Layer Deposition of Antimicrobial Silver Nanoparticles on Textile Fibers. Colloids and Surfaces A: Physicochemical and Engineering Aspects, 289, 105-109. http://doi.org/10.1016/j.colsurfa.2006.04.012

[10] Perelshtein, I., Applerot, G., Perkas, N., Guibert, G., Mikhailov, S. and Gedanken, A. (2008) Sonochemical Coating of Silver Nanoparticles on Textile Fabrics (Nylon, Polyester and Cotton) and Their Antibacterial Activity. Nanotechnology, 19, 245705. http://doi.org/10.1088/0957-4484/19/24/245705

[11] Ritter, W., Knerr, I. and Zoschke, C. (2003) Wässrige Beschichtungszusammensetzung für die Herstellung elektrisch leitfähiger Beschichtungen auf Textilien. EP 1284278 A2 2003.

[12] Green, D.E., Close Jr., L.G. and Van Hyning, D.L. (2004) Textiles Having a Wash-Durable Silver-Ion Based Antimicrobial Topical Treatment. US 6821936 B2 2004.

[13] Mahltig, B., Haufe, H. and Böttcher, H. (2005) Functionalisation of Textiles by Inorganic Sol-Gel Coatings. Journal of Materials Chemistry, 15, 4385-4398. http://doi.org/10.1039/b505177k

[14] Yeo, S.Y., Lee, H.J.O.O. and Jeong, S.H. (2003) Preparation of Nanocomposite Fibers for Pemanent Antibacterial Effect. Journal of Materials Science, 38, 2143-2147. http://doi.org/10.1023/A:1023767828656

[15] Som, C., Halbeisen, M. and Köhler, A. (2009) Integration von Nanopartikeln in Textilien: Abschätzungen zur Stabilität entlang des textilen Lebenszyklus. Empa Swiss Federal Laboratory Materials Testing and Research, 1-45. http://www.empa.ch/nanosafetextiles

[16] Benn, T.M. and Westerhoff, P. (2008) Nanoparticle Silver Released into Water from Commercially Available Sock Fabrics. Environmental Science and Technology, 42, 4133-4139. https://doi.org/10.1021/es7032718

[17] Reidy, B., Haase, A., Luch, A., Dawson, K.A. and Lynch, I. (2013) Mechanisms of 
Silver Nanoparticle Release, Transformation and Toxicity: A Critical Review of Current Knowledge and Recommendations for Future Studies and Applications. Materials (Basel), 6, 2295-2350. https://doi.org/10.3390/ma6062295

[18] Som, C., Nowack, B., Wick, P. and Krug, H. (2010) Nanomaterialien in Textilien: Umwelt-, Gesundheits- und Sicherheits-Aspekte, Fokus: Synthetische Nanopartikel. Empa Swiss Federal Laboratory Materials Testing and Research, 1-58.

[19] Mueller, N.C. and Nowack, B. (2008) Exposure Modelling of Engineered Nanoparticles in the Environment. Environmental Science and Technology, 42, 4447-4453. https://doi.org/10.1021/es7029637

[20] Blaser, S.A., Scheringer, M., MacLeod, M. and Hungerbühler, K. (2007) Estimation of Cumulative Aquatic Exposure and Risk Due to Silver: Contribution of Nano-Functionalized Plastics and Textiles. Science of the Total Environment, 390, 396-409. https://doi.org/10.1016/j.scitotenv.2007.10.010

[21] Li, L., Stoiber, M., Wimmer, A., Xu, Z., Lindenblatt, C., Helmreich, B., et al. (2016) To What Extent Can Full-Scale Wastewater Treatment Plant Effluent Influence the Occurrence of Silver-Based Nanoparticles in Surface Waters? Environmental Science and Technology, 50, 6327-6333. https://doi.org/10.1021/acs.est.6b00694

[22] Sun, Y.Y., Tian, Y., He, M.H., Zhao, Q., Chen, C., Hu, C.S., et al. (2012) Controlled Synthesis of $\mathrm{Fe}_{3} \mathrm{O}_{4} / \mathrm{Ag}$ Core-Shell Composite Nanoparticles with High Electrical Conductivity. Journal of Electronic Materials, 41, 519-523. https://doi.org/10.1007/s11664-011-1800-0

[23] Machunsky, S., Grimm, P., Schmid, H.J. and Peuker, U.A. (2009) Liquid-Liquid Phase Transfer of Magnetite Nanoparticles. Colloids and Surfaces A: Physicochemical and Engineering Aspects, 348, 186-190.

https://doi.org/10.1016/j.colsurfa.2009.07.014

[24] Rudolph, M. and Peuker, U.A. (2011) Coagulation and Stabilization of Sterically Functionalized Magnetite Nanoparticles in an Organic Solvent with Different Technical Polymers. Journal of Colloid and Interface Science, 357, 292-299. https://doi.org/10.1016/j.jcis.2011.02.043

[25] Owens, D.K. and Wendt, R.C. (1969) Estimation of the Surface Free Energy of Polymers. Journal of Applied Polymer Science, 13, 1741-1747.

https://doi.org/10.1002/app.1969.070130815 